\title{
VIBRATION BASED RECONSTRUCTION OF THE CYLINDER PRESSURE IN DIESEL ENGINES BY USING NEURAL NETWORKS
}

Juan Carlos Peña and Grover Zurita

\begin{abstract}
The cylinder pressure curve is a very important parameter for detection of malfunctioning of combustion process in diesel engines. It provides a considerable amount of information about the performance of the engine. The traditional method to get the cylinder pressure curve is to use a cylinder pressure transducer, which is inserted in the cylinder head of the engine. This method is both expensive because of the high cost of the transducer and lifetime limited due to the harsh working environment. Therefore, there is an increasing need of a new non intrusive method, which can be applied for the reconstruction of the cylinder pressure.

The main objective of this paper is to perform the reconstruction of the cylinder pressure curve from vibration measurements by using the Neural Network Method (NNM). The cylinder pressure data obtained with transducers on operating engines was simultaneously recorded with vibration data obtained with external accelerometers at Scania Acoustic Laboratory in Stockholm (Sweden). The measured data were used to train the Neural Networks $(\mathrm{NN})$, thereafter a new data set of vibration signals was enter to the NNs to get the reconstructed cylinder pressure signal. Finally, the results showed high accuracy and precision. The standard deviation of the average maximum cylinder pressures $\left(\bar{P}_{M A X}\right)$ varied between 0.03 and 1.01 percent, much lower than those obtained with other methods i.e. Cepstrum Method and Multivariate Data Analysis (MVDA). The final goal to use the NNM for optimization of the combustion process and engine diagnostics was fulfilled.
\end{abstract}

Keywords: Neural Networks, Radial Basis, Generalized Regression Network, Cylinder Pressure. 